04

\title{
Разработка источника для подачи топлива в центральную зону термоядерного реактора
}

\author{
(C) А.В. Воронин, Н.Н. Бахарев, В.К. Гусев, А.Н. Новохацкий, С.А. Поняев \\ Физико-технический институт им. А.Ф. Иофффе РАН, \\ 194021 Санкт-Петербург, Россия \\ e-mail: voronin.mhd@mail.ioffe.ru
}

(Поступило в Редакцию 20 марта 2017 г.)

\begin{abstract}
Представлены результаты исследований плазменного источника, основанного на коаксиальном ускорителе с щелевой геометрией канала для разгона плазмы с напуском рабочего газа в ускоритель с помощью электродинамического клапана. Проведены измерения параметров плазмы на выходе ускорителя. Щелевой канал ускорителя создавал большее давление струи по сравнению с коаксиальным, особенно на значительных расстояниях от источника. Давление струи достигало $10^{6} \mathrm{~N} / \mathrm{m}^{2}$ на расстоянии $0.7 \mathrm{~m}$. Источник создавал умеренно чистую плазму при токе менее 80 кА. Плотность превышала таковую, полученную с помощью коаксиальной пушки, и составила $(2.5-5) \cdot 10^{22} \mathrm{~m}^{-3}$.
\end{abstract}

DOI: 10.21883/JTF.2018.05.45896.2255

\section{Введение}

Одной из проблем управляемого термоядерного синтеза с магнитным удержанием плазмы является подача топлива в центральную область реактора. Для подпитки международного термоядерного экспериментального реактора (ИТЭР) необходимо инжектировать топливо с большой кинетической энергией. Оценки показывают, что в установке ИТЭР магнитное поле и плазма могут создавать давление $10^{6}-10^{7} \mathrm{~N} / \mathrm{m}^{2}$ [1]. В этих условиях подпитка реактора может быть обеспечена источником с плотностью частиц $\leq 10^{24} \mathrm{~m}^{-3}$ и скоростью потока $\sim 100 \mathrm{~km} / \mathrm{s}$.

В мировой практике устройства ускорения газа, твердых частиц и плазмы изучаются и широко используются для заполнения плазменных устройств. Однако системы импульсной подачи рабочего газа не эффективны. Малоэнергетичные частицы нейтрального газа в основном тормозятся на периферии. Пневматические пушки или центрифуги разгоняют частицы замороженного газа до скорости, не превышающей $3 \mathrm{~km} / \mathrm{s}$ [2]. Скорость твердых частиц $7 \mathrm{~km} / \mathrm{s}$ была достигнута с помощью электромагнитной рельсотронной пушки [3]. Исследования показали, что дальнейшее увеличение скорости вещества невозможно без ионизации и перехода его в плазменное состояние. Коллективное ускорение плазменных колец, удерживаемых тороидальным магнитным полем (компактные торы), создается, например, с помощью пушки Маршала, оснащенной внешним магнитным полем [4]. Поскольку такая плазма удерживается магнитным полем, ее концентрация ограничена, а увеличение массы ускоряемого вещества требует увеличения объема плазмы. Инжекция вещества с помощью высокоэнергичных пучков нейтральных атомов позволяет увеличить плотность плазмы в центральной зоне токамака (скорость движения атомов $\sim 15000 \mathrm{~km} / \mathrm{s}$, плотность $\left.\sim 10^{16} \mathrm{~m}^{-3}\right)$. Применение метода нейтральной инжекции в качестве основного метода подачи топлива в реактор является проблематичным из-за очень высокой стоимости источника ионов MeV-диапазона [5].

Наибольшая плотность плазмы $\left(5 \cdot 10^{26} \mathrm{~m}^{-3}\right)$ была получена в экспериментах с разрядами в узких капиллярных каналах [6]. К сожалению, такая плазма содержала большое количество посторонних примесей и не могла быть использована для заполнения термоядерных установок.

Разработанная в ФТИ им. А.Ф. Иоффе коаксиальная плазменная пушка позволила получить высокоионизованные струи с плотностью частиц $\sim 10^{22} \mathrm{~m}^{-3}$ и скоростью потока $\geq 100 \mathrm{~km} / \mathrm{s}$ [7]. Большая плотность в источнике была достигнута благодаря интенсивному напуску газа в ускоритель. В этом случае газ высвобождался из гранул гидрида титана электрическим разрядом. С таким источником были проведены успешные эксперименты по управлению параметрами плазмы в сферическом токамаке Глобус-М [8]. Недостатком такого источника является относительно большой объем камеры коаксиального ускорителя, которым может определяться величина максимальной плотности плазмы. По аналогии с разрядом в капилляре напрашивается вариант камеры с узким каналом для увеличения плотности плазменной струи.

В настоящей работе представлены результаты исследований плазменного источника, разработанного на основе коаксиального ускорителя с щелевой геометрией канала для разгона плазмы с напуском рабочего газа в ускоритель с помощью электродинамического клапана $[9,10]$. Проведены измерения параметров плазмы на выходе ускорителя - плотности частиц, элементного состава и давления струи. Рассматриваемый источник генерировал достаточно чистую плазму при токе ускорителя $\leq 80 \mathrm{kA}$, обеспечивал более высокое давление струи и плотность частиц по сравнению с пушкой Маршала и источником с напуском газа из гранул гидрида 
титана. Представлен сравнительный анализ параметров ускорителей с коаксиальной и щелевой геометрией канала распространения разряда.

\section{Методика}

Для решения поставленных задач была проведена модернизация стенда плазменной пушки. Стенд состоял из вакуумной камеры объемом $2.5 \mathrm{~m}^{3}$, плазменной пушки и диагностик для измерения параметров плазменной струи (рис. 1). Различные варианты плазменных источников могли присоединяться к вакуумному затвору камеры. Струя плазмы могла свободно вытекать в большой объем камеры без взаимодействия с ее стенками. Пушка типа Маршала содержала коаксиальные электроды для ускорения плазмы и быстродействующий клапан электродинамического типа для напуска рабочего газа в ускоритель. С целью увеличения давления струи был разработан и опробован источник с щелевой геометрией

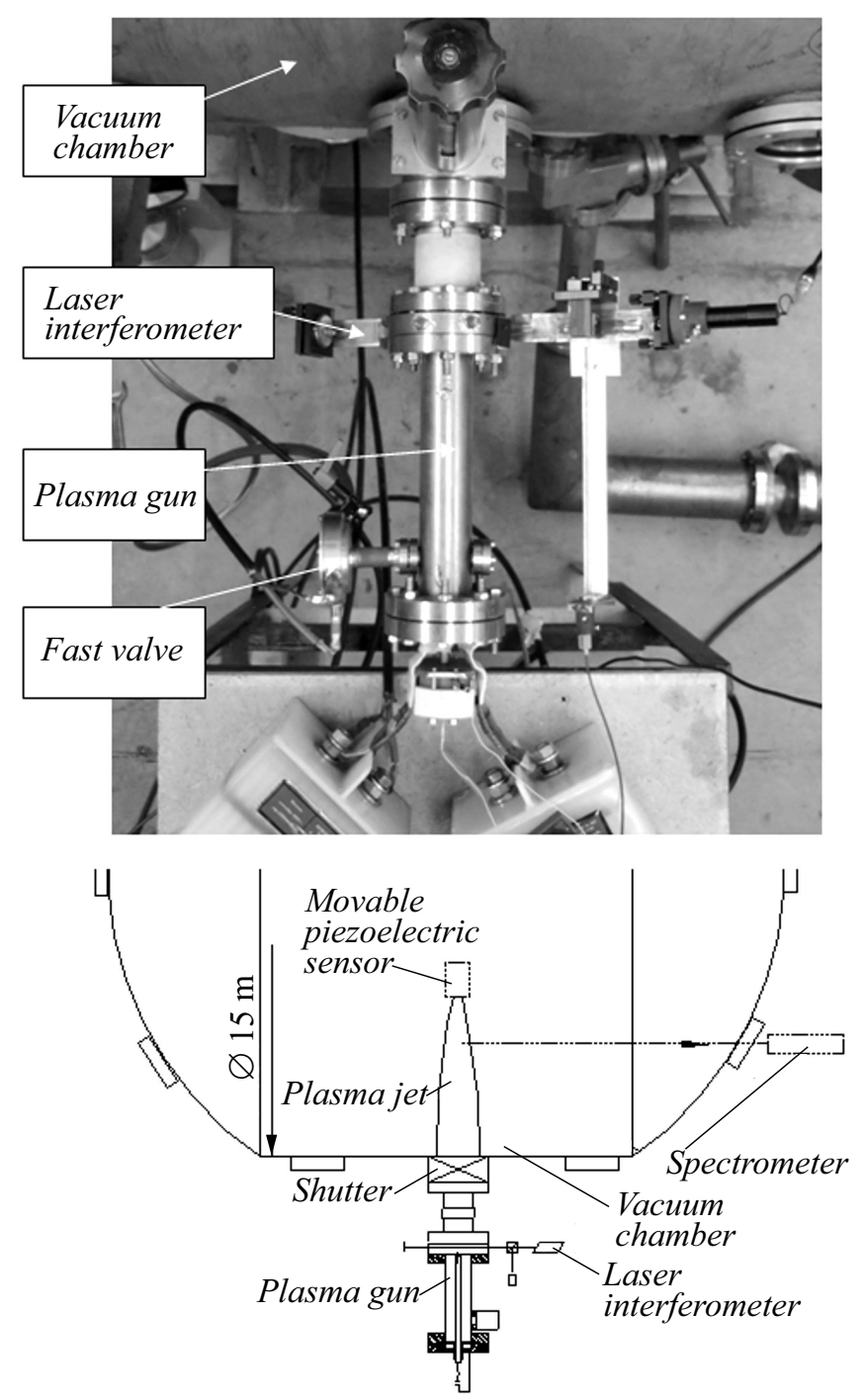

Pис. 1. Плазменная пушка с диагностиками, вид сверху.

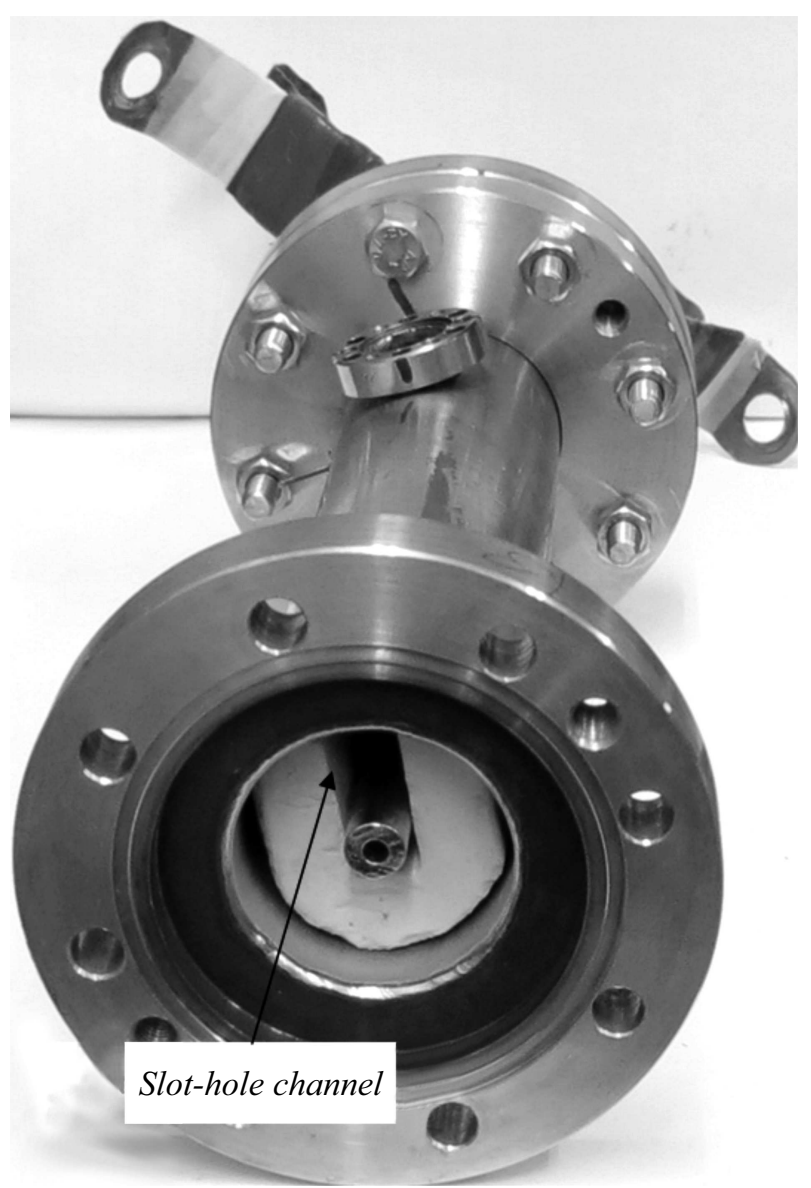

Рис. 2. Коаксиальный ускоритель с щелевым каналом ускорения плазмы.

канала ускорения плазмы. Для этого в пространство между коаксиально расположенными электродами была установлена керамическая вставка с щелевой геометрией. Длина щели составляла $200 \mathrm{~mm}$. Внешний вид коаксиального ускорителя, оснащенного щелевой керамической вставкой, представлен на рис. 2.

Лазерный интерферометр Майкельсона с длиной волны $532 \mathrm{~nm}$ позволял проводить измерение плотности плазмы на выходе ускорителя. Пьезоэлектрический датчик регистрировал давление струи на различных расстояниях от ускорителя. В отличие от ранее используемых датчиков, настоящий детектор был надежно экранирован от электромагнитных наводок и потенциала плазменной струи. Спектральный состав плазмы измерялся по ее излучению с помощью AvaSpec-ULS 2048XL-RS-USB2 в области длин волн от 350 до $1000 \mathrm{~nm}$ на расстоянии $0.5 \mathrm{~m}$ от ускорителя. Методики измерения параметров плазменной струи подробно описаны в работе [11].

\section{Результаты исследований}

Фотографии гелиевой плазменной струи, вытекающей из щелевого ускорителя, представлены на рис. 3. Струя 

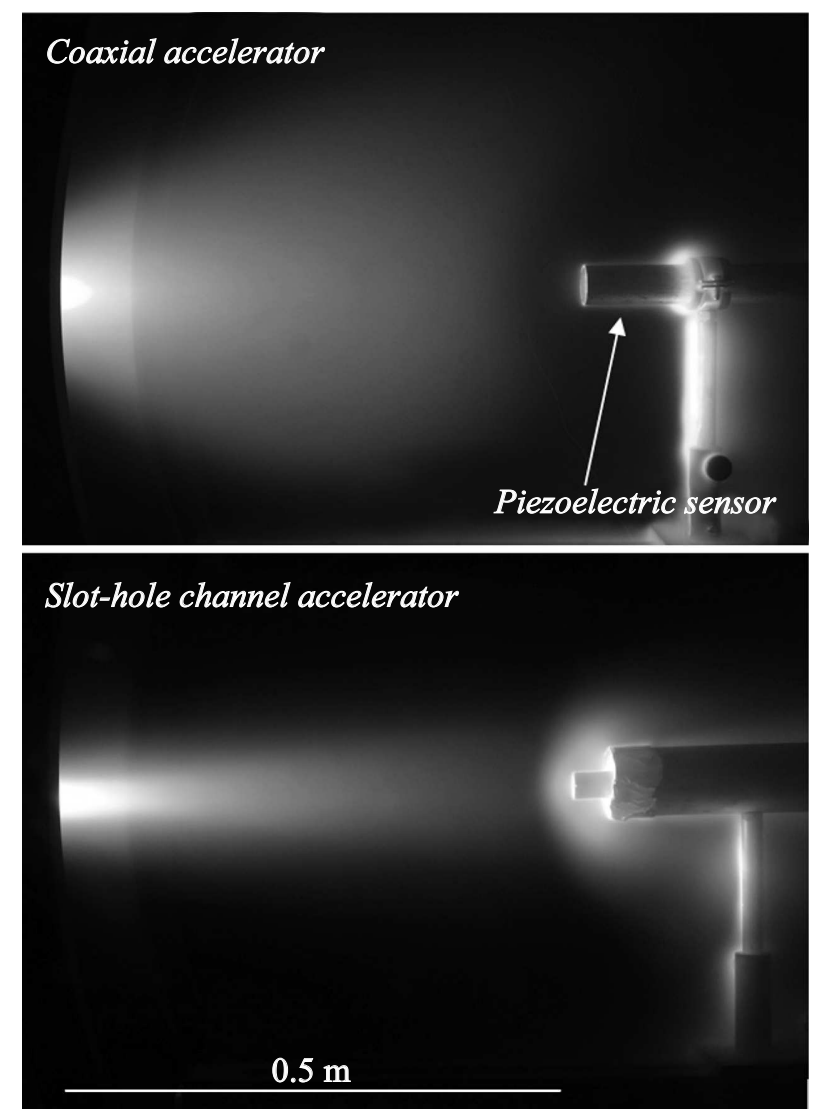

Рис. 3. Видеокадры струи гелиевой плазмы, вытекающей из ускорителей с различной геометрией.

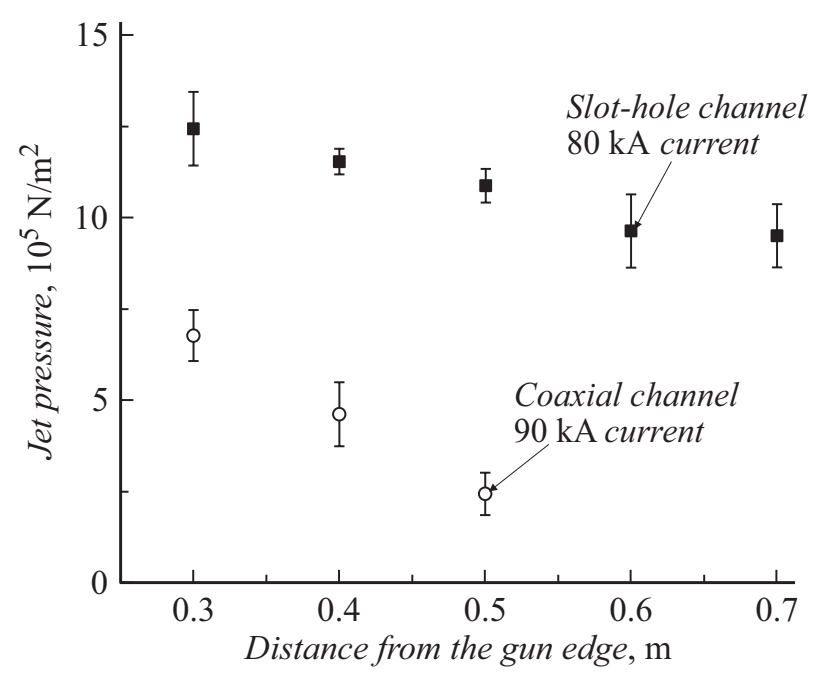

Рис. 4. Зависимость давления плазменной струи от расстояния до ускорителя.

вытекает в вакуумный объем вдали от стенок камеры и сталкивается с датчиком давления, вызывая свечение вблизи его поверхности. Видно, что угол расходимости струи, вытекающей из коаксиального канала, больше, чем угол расходимости струи, вытекающей из щелево- го ускорителя, а расположенный во встречном потоке датчик давления ярко светится.

Измеренные датчиком зависимости давления плазменной струи от расстояния до источника для коаксиального и щелевого каналов представлены на рис. 4. Сравни-

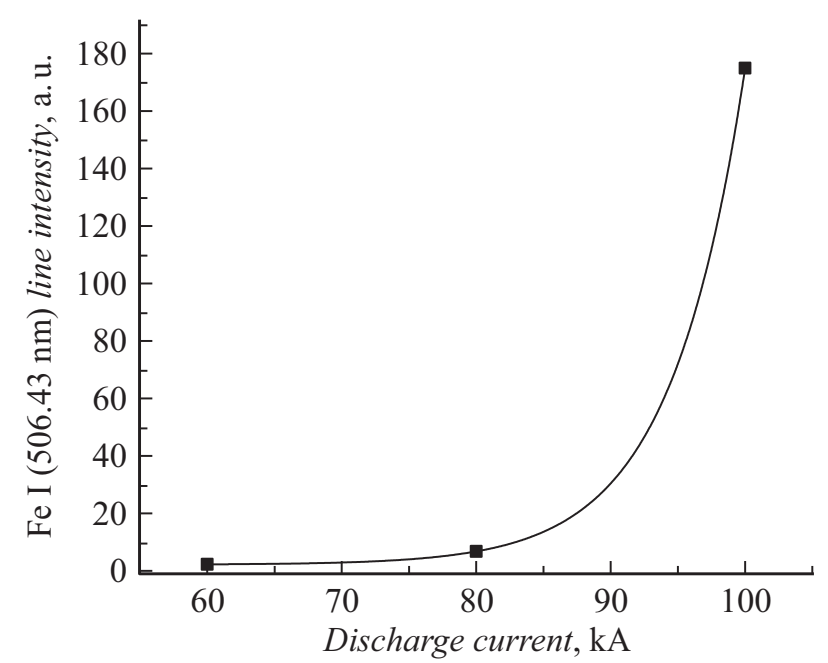

Рис. 5. Зависимость интенсивности излучения примеси железа от тока ускорителя.

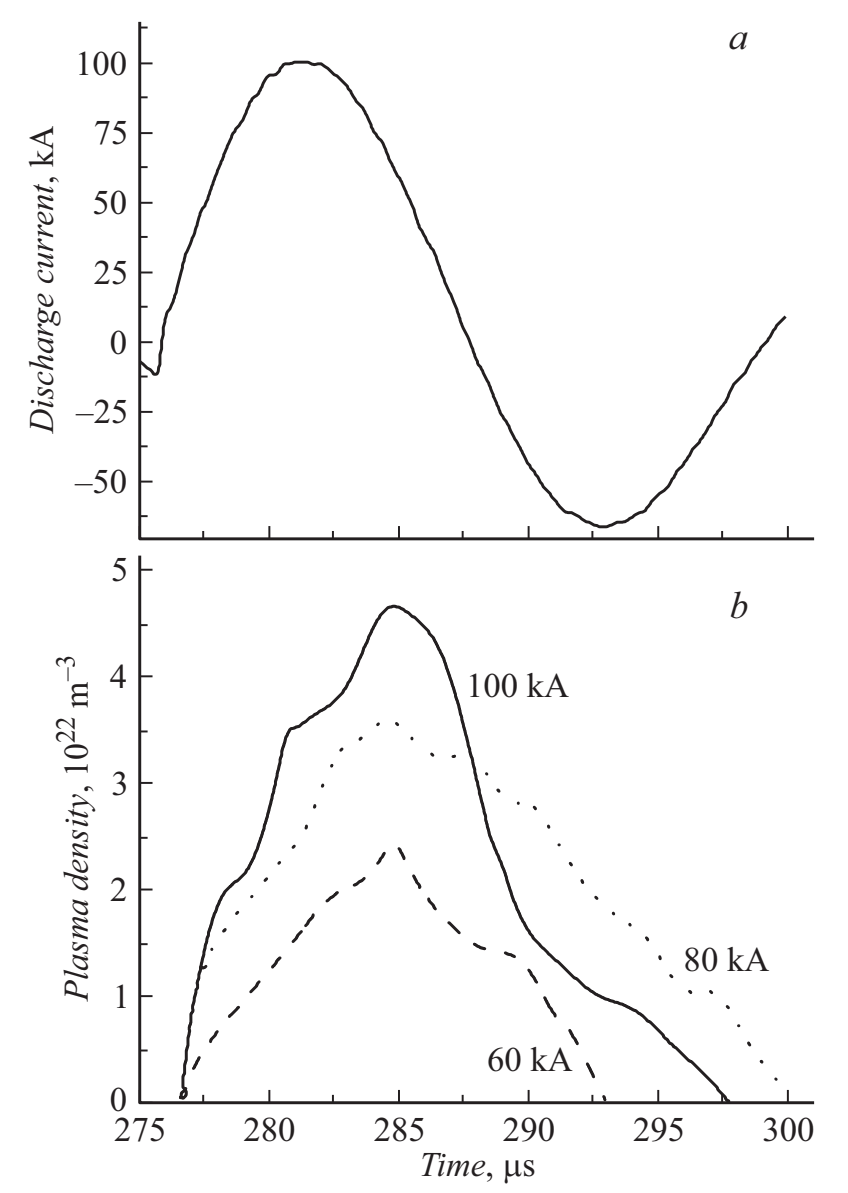

Рис. 6. Зависимость тока $(a)$ и плотности плазмы $(b)$ от времени для различных токов ускорителя. 
тельный анализ коаксиального и щелевого ускорителей показал, что щелевой канал ускорителя создавал большее давление струи по сравнению с коаксиальным, особенно на больших расстояниях от источника. На расстоянии 0.7 m давление струи могло достигать $10^{6} \mathrm{~N} / \mathrm{m}^{2}$.

Спектр излучения плазменной струи, измеренный на расстоянии $0.5 \mathrm{~m}$ от источника, представлен на рис. 5 . Видно, что меньший ток, ускоряющий плазму, создавал меньшее поступление примесей. Источник генерировал умеренно чистую плазму при токе менее $80 \mathrm{kA}$. Однако интенсивность излучения примеси железа увеличивалась более чем в 50 раз при токе ускорителя $>80 \mathrm{kA}$.

Характерная зависимость изменения тока ускорителя от времени представлена на рис. 6, $a$. Измеренные зависимости плотности плазмы от времени для различных токов в ускорителе представлены на рис. $6, b$. Щелевой ускоритель обеспечивал более высокую плотность плазменной струи по сравнению с коаксиальным. Видно, что при меньшем токе генерировалась плазма с меньшей плотностью. Плотность, достигаемая в этом эксперименте, превышала плотность, полученную с помощью коаксиальной пушки, и составляла $(2.5-5) \cdot 10^{22} \mathrm{~m}^{-3}$.

\section{Заключение}

Проведены исследования плазменной пушки с щелевой геометрией канала ускорения. Получена относительно чистая плазменная струя при токе разряда менее $80 \mathrm{kA}$. Щелевой ускоритель обеспечивал более высокое давление и плотность плазменной струи по сравнению с коаксиальным, особенно на больших расстояниях от источника. Возможная причина улучшения параметров заключается в уменьшении объема камеры для ускорения плазмы. Планируется проведение исследований источника плазмы рельсотронного типа в керамической камере с щелевым ускорительным каналом.

Работа выполнена при частичной поддержке РФФИ (проект № 16-08-00338 а) и ФТИ им. А.Ф. Иоффе.

\section{Список литературы}

[1] ITER Physics Basis. // Nucl. Fusion. 2007. Vol. 47. P. S1-S17.

[2] Combs S.K. // Rev. Sci. Instrum. 1993. Vol. 64. P. 1979.

[3] Drobyshevsky E.M., Zhukov B.G., Sakharov V.A. // IEEE. Trans. Magn. 1995. Vol. 31. P. 299.

[4] Raman R., Martin F., Quirion B. et al. // Phys Rev. Lett. 1994. Vol. 73. P. 3101.

[5] ITER Physics Basis. // Nucl. Fusion. 1999. Vol. 39. P. 2416.

[6] Семенов В.К., Спекторов Л.А. // ЖТФ. 1964. Т. 34. С. 853.

[7] Voronin A.V. et al. // Nukleonika. 2008. Vol. 53. P. 103.

[8] Gusev V.K. et al. // Nucl. Fusion. 2011. Vol. 51. P. 1-12.

[9] Bakharev N.N., Bormatov A.A., Gusev V.K., Goryaionov V.Yu., Iblyaminova A.D., Novokhatsky A.N., Ponyaev S.A., Sakharov N.V., Voronin A.V. Development of the high kinetic energy plasma jet for central fuelling 43rd EPS Conf. Plasma Phys. 4-8 July Leuven, Belgium, 2016. Vol. 40A. ISBN: 2-914771-99-1 P2.067.
[10] Воронин А.В., Бахарев Н.Н., Гусев В.К., Горяинов В.Ю., Ибляминова А.Д., Новохацкий А.Н., Поняев С.А., Сахаров Н.В. Разработка источника для подачи топлива в центральную зону термоядерного реактора. Тез. XLIV Междунар. (Звенигородская) конф. по физике плазмы и управляемому термоядерному синтезу. 13-17 февраля, 2017. C. 76.

[11] Воронин А.В., Гусев В.К., Герасименко Я.А., Судьерков Ю.В. // ЖТФ. 2013. Т. 58. Вып. 8. С. 3642. (Voronin A.V., Gusev V.K., Gerasimenko Ya.A., Sud'enkov Yu.V. // Techn. Phys. 2013. Vol. 58. N 8. P. 1122 1128.) 